\title{
A propagation-measurement-based evaluation of channel characteristics and models pertinent to the expansion of mobile radio systems to frequencies beyond $2 \mathrm{GHz}$
}

\author{
Citation for published version (APA): \\ Bultitude, R. J. C., Schenk, T. C. W., Op den Kamp, N. A. A., \& Adnani, N. (2007). A propagation-measurement- \\ based evaluation of channel characteristics and models pertinent to the expansion of mobile radio systems to \\ frequencies beyond $2 \mathrm{GHz}$. IEEE Transactions on Vehicular Technology, 56(2), 382-388. \\ https://doi.org/10.1109/TVT.2006.889566
}

DOI:

10.1109/TVT.2006.889566

Document status and date:

Published: 01/01/2007

\section{Document Version:}

Publisher's PDF, also known as Version of Record (includes final page, issue and volume numbers)

\section{Please check the document version of this publication:}

- A submitted manuscript is the version of the article upon submission and before peer-review. There can be important differences between the submitted version and the official published version of record. People interested in the research are advised to contact the author for the final version of the publication, or visit the DOI to the publisher's website.

- The final author version and the galley proof are versions of the publication after peer review.

- The final published version features the final layout of the paper including the volume, issue and page numbers.

Link to publication

\footnotetext{
General rights

- You may freely distribute the URL identifying the publication in the public portal. follow below link for the End User Agreement:

www.tue.nl/taverne

\section{Take down policy}

If you believe that this document breaches copyright please contact us at:

openaccess@tue.nl

providing details and we will investigate your claim.
}

Copyright and moral rights for the publications made accessible in the public portal are retained by the authors and/or other copyright owners and it is a condition of accessing publications that users recognise and abide by the legal requirements associated with these rights.

- Users may download and print one copy of any publication from the public portal for the purpose of private study or research.

- You may not further distribute the material or use it for any profit-making activity or commercial gain

If the publication is distributed under the terms of Article $25 \mathrm{fa}$ of the Dutch Copyright Act, indicated by the "Taverne" license above, please 


\title{
A Propagation-Measurement-Based Evaluation of Channel Characteristics and Models Pertinent to the Expansion of Mobile Radio Systems to Frequencies Beyond $2 \mathrm{GHz}$
}

\author{
Robert J. C. Bultitude, Senior Member, IEEE, Tim C. W. Schenk, Member, IEEE, \\ Nicole A. A. Op den Kamp, and Nikhil Adnani
}

\begin{abstract}
This paper concerns the measurement-based comparison of urban microcellular mobile radio channel characteristics at 1.9 GHz and a higher frequency, i.e., $5.8 \mathrm{GHz}$, where future wireless systems could operate. Characteristics that are reported include transmission loss, root-mean-square delay spread, frequency correlation, and envelope fading statistics. Conclusions are drawn concerning whether significant differences in the performance of mobile radio links operating under the same signalto-noise ratio conditions in the two bands would be expected in the area where the measurements were made.
\end{abstract}

Index Terms-Correlation bandwidth, fading channels, frequency correlation, frequency-selective fading, multipath channels, radio channel modeling, radio propagation measurements, transmission loss.

\section{INTRODUCTION}

A S A RESULT of worldwide demand for the expansion of mobile radio systems by allowing operation in higher frequency bands, it is of interest to determine if significant design changes would be needed if microcellular systems at frequencies near $2 \mathrm{GHz}$ were shifted to a higher frequency band. This paper provides some of the required knowledge through a comparison of key propagation characteristics in the same coverage area at 1.9 and $5.8 \mathrm{GHz}$. Where possible, comparisons are made with results of other similar studies [1]-[3].

\section{Measurements And EQuipment}

Measured data were recorded during sequential continuouswave $(\mathrm{CW})$ and pseudonoise channel sounding experiments

Manuscript received November 18, 2003; revised December 20, 2004, October 3, 2005, February 7, 2006, and February 27, 2006. The review of this paper was coordinated by Prof. A. Abdi.

R. J. C. Bultitude and N. Adnani are with the Communications Research Centre, Ottawa, ON K2H 8S2, Canada (e-mail: robert.bultitude@crc.ca; nikhil.adnani@crc.ca).

T. C. W. Schenk was with the Telecommunications Technology and Electromagnetics Group, Eindhoven University of Technology, 5600 MB Eindhoven, The Netherlands. He is now with Philips Research, Connectivity Systems and Networks Group, 5656 AE Eindhoven, The Netherlands (e-mail: tim. schenk@philips.com).

N. A. A. Op den Kamp was with the Telecommunications Technology and Electromagnetics Group, Eindhoven University of Technology, $5600 \mathrm{MB}$ Eindhoven, The Netherlands. She is now with Philips Medical Systems, 5680 DA Best, The Netherlands (e-mail: nicole.op.den.kamp@philips.com).

Digital Object Identifier 10.1109/TVT.2007.889566
[4], [5] in the downtown section of Ottawa, ON, Canada, at center frequencies of 1.9 and $5.8 \mathrm{GHz}$ (hereinafter referred to as 2 and $6 \mathrm{GHz}$ for convenience). Similar measurements were also made at $2 \mathrm{GHz}$ in urban Toronto, ON, some years earlier, and in the line-of-sight (LOS) CW case, some measurements from that data pool were used in modeling reported herein. At both center frequencies, transmission with an effective isotropic radiated power of $+36 \mathrm{dBm}$ was from a biconical antenna mounted at $7.8 \mathrm{~m}$ above the sidewalk along urban streets. Measurements at 2 and $6 \mathrm{GHz}$ were made on different days and on LOS, as well as on parallel and perpendicular non-line-of-sight (NLOS) streets. CW measurements were made on all streets within $1 \mathrm{~km}$ of each of two transmit (Tx) sites in Ottawa and within the same distance of five Tx sites in Toronto. Wideband measurements reported here were only from street sections within two city blocks of the Ottawa Tx sites. This restriction is required to ensure that the signal-to-noise ratio (SNR) in impulse response estimates was greater than or equal to $20 \mathrm{~dB}$ for all data contributing to comparisons reported here. In the $\mathrm{CW}$ case, the narrower receiver bandwidth resulted in a lower receiver noise floor, allowing the analysis of data from greater ranges.

Reception at each center frequency was via a tuned quarterwavelength monopole mounted in the center of the roof of a minivan. In situ radiation patterns were measured to be omnidirectional within $\pm 3 \mathrm{~dB}$. The minivan was driven at normal traffic speeds throughout the urban centers, while off-air signals at the receiver $(\mathrm{Rx})$ were quadrature down-converted and sampled at either $10 \mathrm{Msamples} / \mathrm{s}$ or $2 \mathrm{ksamples} / \mathrm{s}$ per quadrature channel for operation in the wideband and $\mathrm{CW}$ modes, respectively.

In the wideband mode, 511 chip pseudonoise sequences were transmitted at a rate of $5 \mathrm{Mchips} / \mathrm{s}$. Since all Tx and Rx oscillators were slaved to phase-coherent rubidium standards, and all clocks ran continuously, the recorded data are suitable for the time-series-type analyses reported. Calibration results [4] show that the ratio of root-mean-square (rms) delay spreads for backto-back measurements in the 2- and 6-GHz bands was 0.96 . Since this is greater than the ratio of the medians from experiments (reported later in this paper), it is considered that equipment effects on the desired comparisons were insignificant.

Data postprocessing resulted in a time series of estimates for the cross correlation between the sounding sequence and the received sequence (XCEs) that had an effective sample 


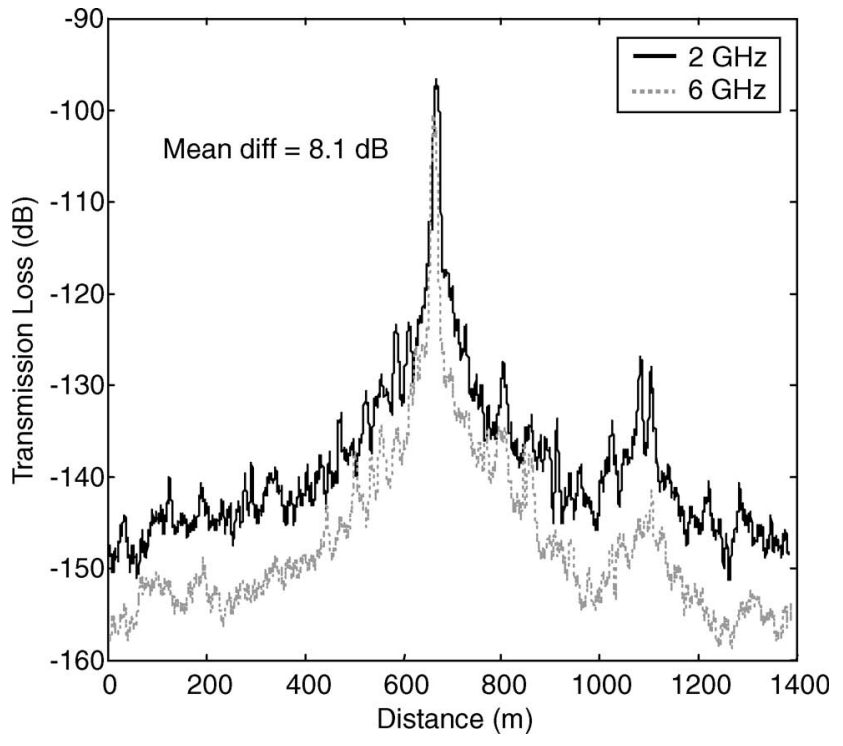

Fig. 1. Comparison of measured power loss at frequencies near 2 and $6 \mathrm{GHz}$ on a street that ran perpendicular to the LOS street.

rate of $450 \mathrm{XCEs} / \mathrm{s}$. The authors are reluctant to refer to these as radio channel impulse response estimates, because the sounding bandwidth was not much greater than that of communications systems being considered for the future. However, the $10-\mathrm{MHz}$ bandwidth is considered adequate for the comparisons herein, since it was the same at both 2 and $6 \mathrm{GHz}$. The $450-\mathrm{XCE} / \mathrm{s}$ sample rate was chosen to accommodate the fading rates expected at $6 \mathrm{GHz}$.

Distance traveled was not recorded during the wideband measurements. Measurement runs using this mode only lasted 1 min due to memory limitations. During the $\mathrm{CW}$ experiments, however, recording intervals were longer, and distance was estimated every quarter of a second. CW measurement runs typically lasted long enough to travel more than $1 \mathrm{~km}$.

\section{TRANSMISSION LOSS}

A comparison of 40-wavelength running averages of received CW power showed no obvious changes in the difference between transmission loss at the two frequencies for streets with different orientations. There were similar random variations in this difference on all streets. Fig. 1 shows results for a street seven blocks from the Tx that ran perpendicular to the LOS street. A large peak at the intersection with the LOS street (at $650 \mathrm{~m}$ ), as well as a general trend of increasing transmission loss with increasing distance from this intersection, can be seen. Other peaks occur at intersections with parallel streets and near open areas between high-rise buildings. On parallel streets (i.e., streets that ran parallel to the LOS street), there are similar characteristics. In addition, a trend of increasing transmission loss as a function of the distance of the parallel street from the Tx site is clear. The slope of this trend also decreases as a function of distance from the Tx site. A similar structure for transmission loss in microcells in Ottawa was previously reported in [6].

Fig. 1 is typical of all LOS and NLOS measurements in showing no significant dependence of the difference in trans-

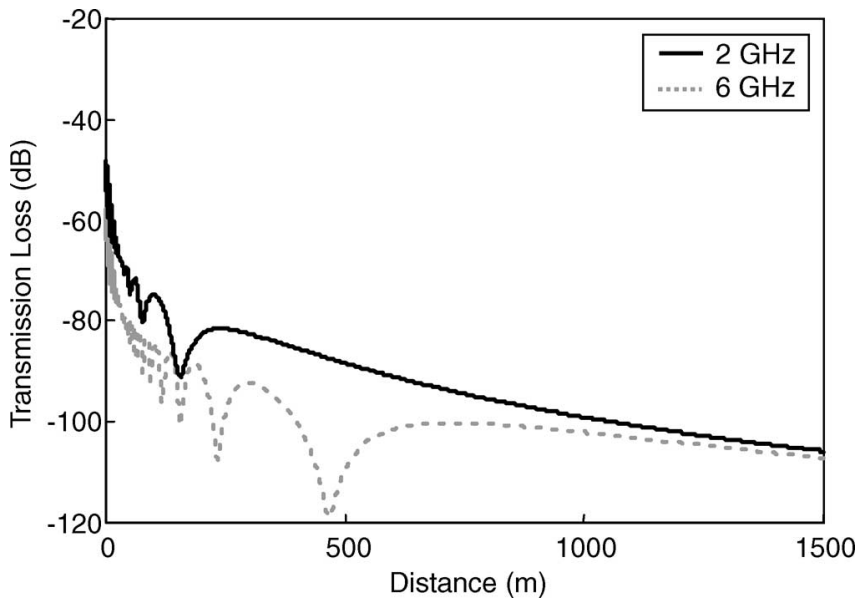

Fig. 2. Comparison of two-ray model results for the same transmit/receive geometry.

mission loss on the Tx-Rx range. This allows the determination of an area-wide average for this difference, which was estimated every meter along each of the 23 streets. An experimentally determined cumulative distribution function (ECDF) for its cumulative probability distribution was also found. For measurements with one Tx site, the ECDF was found to compare well with a lognormal distribution having a mean of $12 \mathrm{~dB}$ and a standard deviation of $4 \mathrm{~dB}$. For the other Tx site, which was one city block to the west on a perpendicular street, the appropriate model was also lognormal with a standard deviation of about $4 \mathrm{~dB}$, but it had a mean of $7 \mathrm{~dB}$. These results compare well with those reported in [3] for several districts in Tokyo.

Consideration of the difference in effective areas of tuned monopole $\mathrm{Rx}$ antennas at the two frequencies leads one to expect that if there were no fading and no obstructions, the difference in received power would be given by the square of the ratio of wavelengths, which is $9.5 \mathrm{~dB}$. Although the standard deviations of the results for the two Tx sites are consistent, the mean differences lie on either side of this 9.5- $\mathrm{dB}$ ratio.

It is believed that the disparity of the mean differences can be partially explained by observation of the difference in the fading patterns of the running means at the two frequencies. This pattern occurs over distances on the order of a few meters and is often referred to as shadow fading. It is a result of both multipath interference and the obstruction of impinging waves (whether directly from the Tx or via multipath sources) by obstacles. Some now consider [7]-[9] that the term shadowing and the mechanisms that cause large-scale fading are often misunderstood. Shadow fading, or large-scale fading evidenced by variations in average received signal power from one local area to another, should not be associated solely with variations in obstruction to LOS between the Tx and Rx antennas. This is demonstrated by comparison of results in Fig. 2, calculated from a simple two-ray model that considers a direct ray and a single ground-reflected ray. This is a clear example of a difference in large-scale (shadow) fading at the two frequencies in the absence of any obstruction losses-fixed or variable. The mean difference between transmission loss at the two frequencies in this example is $13 \mathrm{~dB}$, and the standard deviation is $7 \mathrm{~dB}$. The distribution for this difference, however, was found not to compare well with a lognormal model. 
In real-world environments, the multipath situations are considerably more complicated than those associated with the tworay model. It is therefore considered reasonable that differences would exist in the large-scale multipath fading patterns along different streets into which energy would have been coupled from the two Tx sites via different paths and mechanisms (e.g., through buildings and gaps between buildings). Furthermore, diffraction effects [1], which would always result in more loss at the higher frequency, would result in greater loss differences than those attributable to the effective aperture ratio. The combination of these effects could have easily resulted in the observed positive and negative disparities from that ratio for measurements centered on the two Tx sites.

Results from the 2-GHz CW measurements were used to evaluate various microcellular channel propagation loss models [10]-[12]. Some model extensions were also proposed [5]. On LOS streets, the best fits to 40-wavelength running averages of received power were obtained using the modified two-ray model reported by Oda et al. [10]. This model extends the basic two-ray model by using a visibility parameter, which is denoted as $s$, to account for obstruction of the direct and groundreflected rays by vehicles, signs, etc. The received power of the basic two-ray model is multiplied with $e^{-s r}$, where $r$ is the separation between the Tx and Rx. The cited model also makes allowance for the case that the secondary ray might come from a vehicle roof rather than the street surface by considering the average height of the Tx and Rx antennas to be lower than they actually are. This reduction in the antenna height is denoted by $h_{0}$. Transmission results from $182-\mathrm{GHz}$ Ottawa and Toronto LOS street sections having lengths between 300 and $400 \mathrm{~m}$ were compared with this model. The best fits were obtained for values of $h_{0}$ ranging between 0.6 and $1.6 \mathrm{~m}$ and $s$ between 0 and 0.005 . The median value for $s$ was 0.0025 , and that for $h_{0}$ was $1.2 \mathrm{~m}$.

In addition to finding the best fit models for each of the 18 LOS street sections, a general model with $h_{0}=1.2 \mathrm{~m}$ and $s=0.001$ was determined, which gave reasonable fits in most LOS cases. Differences of the 40-wavelength running mean of experimental results from this model had means that ranged between -4 and $14 \mathrm{~dB}$ with a median of $2 \mathrm{~dB}$ and had rms deviations with respect to the model that ranged between 3 and $16 \mathrm{~dB}$.

Good models for the parallel and perpendicular streets were more difficult to find because of the infusion of energy from each intersection in addition to that coupled through gaps between buildings. On perpendicular streets, reasonable success was obtained for distances of up to $300 \mathrm{~m}$ from the LOS street using a virtual source model reported in [11]. The parameter set for the associated generalized model is given as follows: $W_{s}=20 \mathrm{~m}, x=2 \mathrm{~m}, r_{s}$ as per the area map, and $\alpha=0.2$, where $W_{s}$ represents the width of the perpendicular street, $x$ represents the distance of the base station antenna from the adjacent building wall, $r_{s}$ represents the distance (in meters) from the base station to the centerline of the perpendicular street, and $\alpha$ is a model parameter described in [11]. Using this model for propagation loss on 15 different trajectories along streets within five city blocks of the Ottawa Tx sites resulted in rms variations of experimentally determined 40-wavelength means with respect to the model that ranged between 2.5 and $9 \mathrm{~dB}$.

A modified virtual source model [12] was tested for parallel streets. The modifications were intended to allow propagation through and between buildings. Results with about the same accuracy as those reported for the other streets were eventually obtained for each street section. However, no consistencies were found that would allow for the reporting of a "generalized" model as for the other street types.

\section{Multipath Dispersion}

To parameterize multipath dispersion, rms delay spread values were estimated from average power delay profiles (APDPs). These were derived from XCEs, as defined in Section II, using a noise exclusion threshold [13] chosen such that one noise spike could have been mistaken for a multipath component in every 100 XCEs. This threshold would have automatically been set higher at $6 \mathrm{GHz}$ because of the greater transmission loss and concomitant lower SNR at the receiver. There is therefore a degree of uncertainty regarding rms delay spread comparisons. Nevertheless, such comparisons were made and considered along with other results in order to draw conclusions. Averaging was over the first 500 XCEs in each of 45 time series measurements at each frequency. Resulting time series were found to always possess wide sense stationary (WSS) characteristics, as evaluated at selected spectral lines within the sounding bandwidth using the Runs test [14].

Although measurements at the two frequencies were conducted on different days, the majority of wideband channel characteristics were estimated using (paired) data files from approximately the same street sections. This gave what is considered to be equivalent representation within the data pools at 2 and $6 \mathrm{GHz}$. Data from street sections where measurements were made at only one frequency or the other were also used to contribute to ECDFs. Consecutive measurements within the data sets used for analyses reported here were determined to be almost uncorrelated by means of scatter plots. Thus, the contribution of each of the APDPs is considered to be significant. The pairing of observations from the same street section at the two frequencies is also considered to have enhanced the probability of a good comparison. Fig. 3 shows a scatter plot of rms delay spreads from the paired data files.

It can be seen that most of the time, the comparisons were concentrated about the equivalence line, although there were a significant number of outliers that indicate greater dispersion at $2 \mathrm{GHz}$ than at $6 \mathrm{GHz}$. These instances primarily occurred at greater distances from the Tx. ECDFs were also estimated from the total pool of rms delay spread results, including those from unpaired street sections, and are shown in Fig. 4.

Up to about the 80th percentile, the ECDFs are very similar. According to the Kolmogorov-Smirnov (KS) test [15], the 45 data used to compile the ECDFs result in $90 \%$ confidence boundaries that lie at approximately 18 percentage points above and below the plotted values. Visual examination cannot therefore be used to draw conclusions about whether or not the ECDFs represent the same population. Another application of 


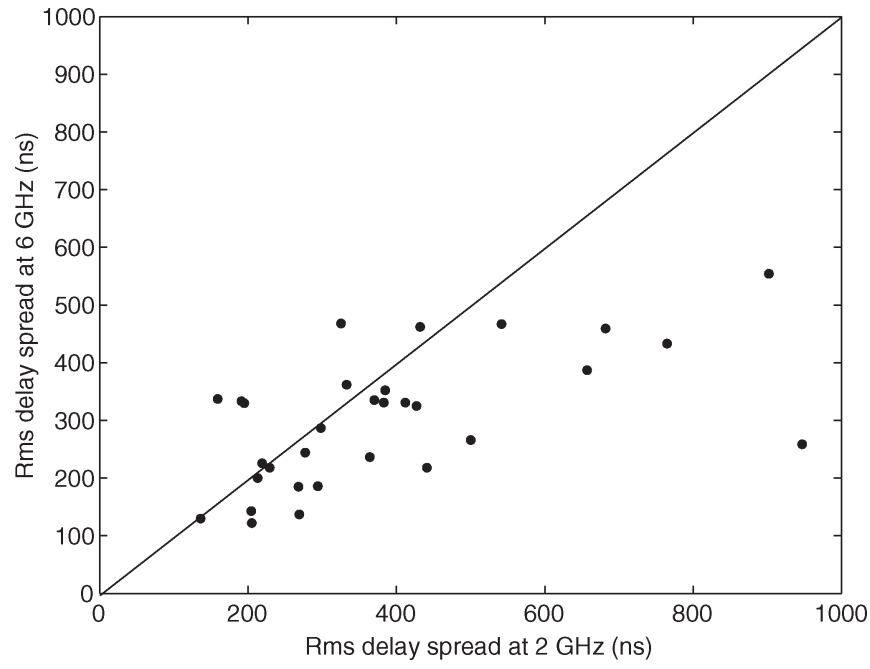

Fig. 3. Comparison of rms delay spreads at 2 and $6 \mathrm{GHz}$.

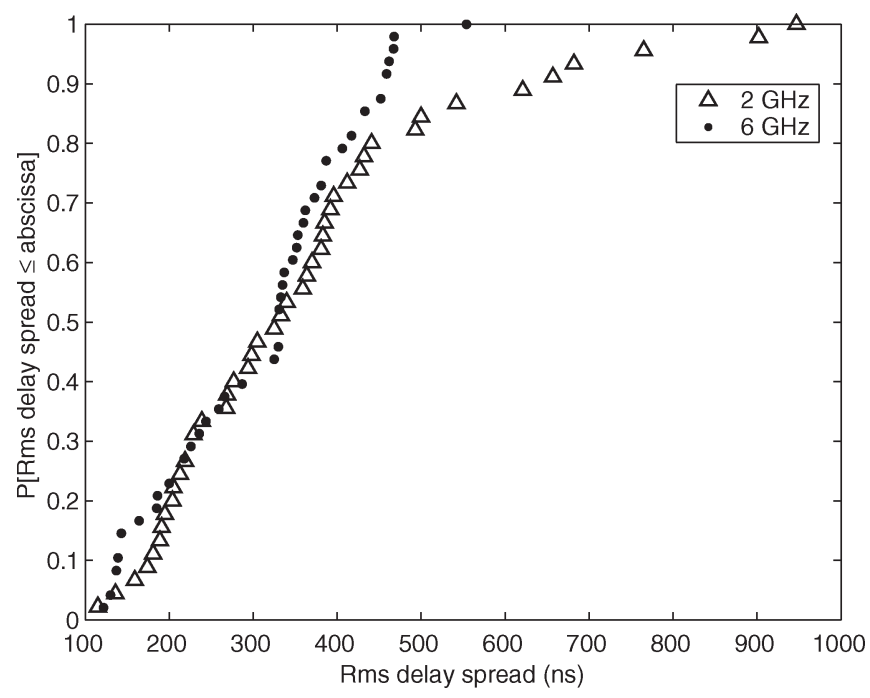

Fig. 4. ECDFs for rms delay spreads at 2 and $6 \mathrm{GHz}$.

two-sample version ${ }^{1}$ of the KS test, however, can be used for this purpose. If this test is conducted at the $1 \%$ significance level (i.e., such that there is only $1 \%$ probability of an incorrect decision to reject the null hypothesis that the ECDFs represent the same population), the null hypothesis cannot be rejected. Yet another calculation using an equation for approximating the KS distribution [16] shows that if the critical level for rejection of the null hypothesis were placed exactly at the maximum discrepancy between the ECDFs and the null hypothesis was rejected, the probability that such a decision would be in error is $86 \%$. These are all strong indicators that there is no significant difference in the underlying distribution of rms delay spreads at 2 and $6 \mathrm{GHz}$.

The correlation between random variations of rms delay spreads at the two frequencies as a function of location is also

\footnotetext{
${ }^{1}$ In the two-sample version, two experimental results are compared rather than one experimental result and a model. Thus, the errors normally attributed to estimating the model parameters from the measurements are not of concern. However, the number of samples used as an index in the standard table of critical values is modified to be $N=m_{1} m_{2} /\left(m_{1}+m_{2}\right)$, where $m_{1}$ and $m_{2}$ are the number of independent samples in the two experiments [16].
}

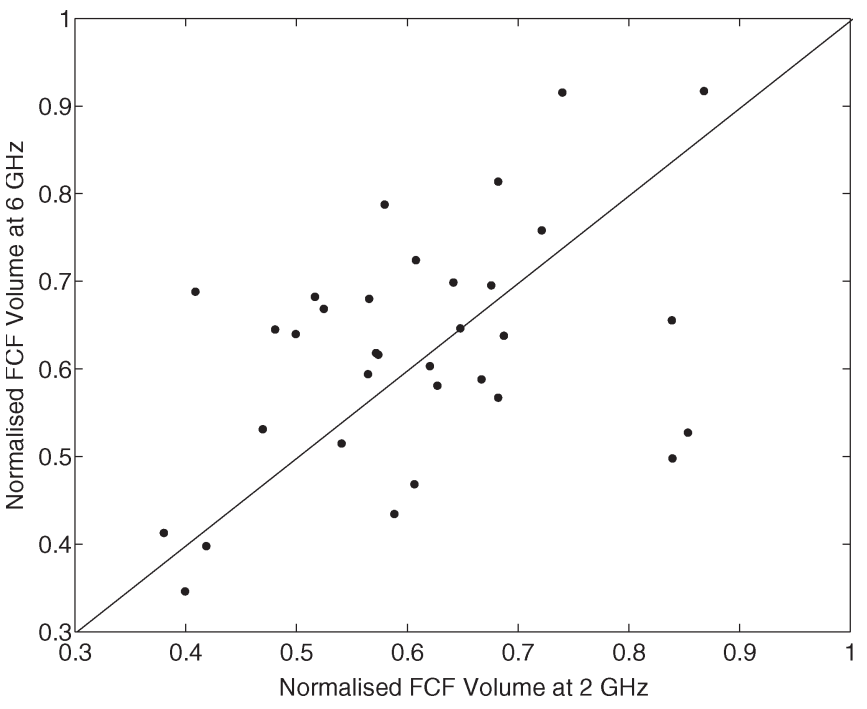

Fig. 5. Comparison of values of $\nu$ for a 4-MHz bandwidth.

of interest. An estimation of this was made possible because of the paired data files and gave a correlation coefficient of 0.87 .

\section{Frequency CorRelation}

As reported in [17], the normally applied Fourier transform relationship between APDPs and frequency correlation functions (FCFs) is not always valid, and the relationship between rms delay spreads and coherence bandwidths can be complicated [18]. This makes it necessary to consider both measures in comparing channel characteristics. The method reported in [17] was therefore used to estimate FCFs from the measured XCE time series. A comparison [4] for street sections that exhibited Rayleigh fading showed that many of the two-sided $50 \%$ coherence bandwidths were greater at $6 \mathrm{GHz}$. However, the medians are approximately the same, with that at $2 \mathrm{GHz}$ being $3.6 \mathrm{MHz}$ and that at $6 \mathrm{GHz}$ being $3.8 \mathrm{MHz}$. The best and worst cases, which are represented by the largest and smallest correlation bandwidths, respectively, are also approximately the same at the two frequencies, being 7.0 MHz and 1.5 MHz.

On Rician channels, the presence of the deterministic component of the received signal results in very high coherence (>90\%) across very large bandwidths. This prohibits the estimation of $50 \%$ or even $90 \%$ coherence bandwidths. However, the normalized volume $\nu$ of 3-D FCFs that result from using the method in [17] can be estimated, regardless of the envelope fading distribution. It can also be related to mobile digital link performance [19]. Therefore, in consideration of IMT2000 systems, values for $\nu$ were estimated and normalized over 4-MHz bandwidths. Results for the 45 measurement runs are shown in Fig. 5.

It is observed that the scatter is more evenly centered on the equivalence line than in the case of the rms delay spreads. A comparison of the statistics of $\nu$ in the measurement area is shown by the ECDFs in Fig. 6 .

The discrepancies between the EDFCs in Fig. 6 are smaller than those for the rms delay spreads in Fig. 3. A KS test at the $1 \%$ significance level indicated the null hypothesis that the ECDFs represent the same underlying population should not be 


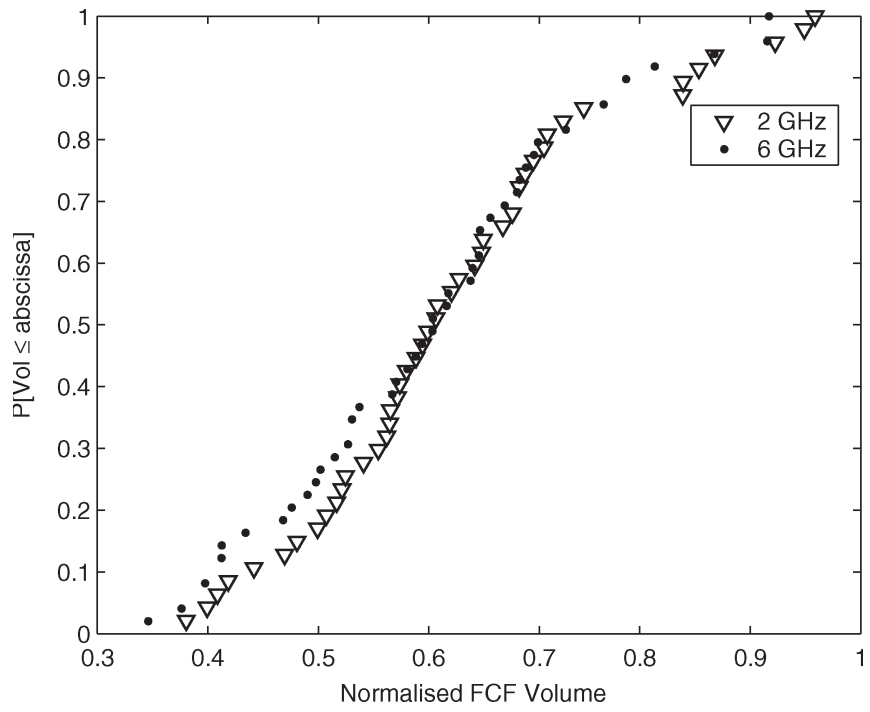

Fig. 6. Comparison of the ECDFs for $\nu$.

rejected. If the rejection threshold were placed exactly at the maximum discrepancy between the ECDFs, the probability of error associated with a decision to reject the null hypothesis would be $98 \%$. Thus, it is concluded that the distribution of $\nu$ is also approximately the same for frequency bands near 2 and $6 \mathrm{GHz}$. The correlation coefficient for variations of $\nu$ in the two bands as a function of location in the measurement area was 0.97 .

The similarity in the distributions of values for rms delay spread and $\nu$ in the 2- and 6-GHz frequency bands is considered by the authors to indicate that similar mobile digital link performance can be expected whenever multipath dispersion is dominant in the determination of achievable bit error rates. However, on Rician channels, the probability of error value at the error-rate floor is influenced more significantly [19] by the depth of envelope fading than it is by values of either $\nu$ or rms delay spread. Higher Rice factors (defined here as the deterministic/random power ratio) result in lower error-rate floors.

\section{ENVELOPE FADING}

Rice factors, which reflect fade depths, were estimated for individual spectral lines in the received wideband sounder measurements for the paired data files using the method reported in [20]. Their distribution was found to be similar at 2 and $6 \mathrm{GHz}$. In addition, to add to the statistical significance of such narrowband fading estimates, the $\mathrm{CW}$ data were analyzed over hundreds of short (WSS) intervals on all streets. Globally, histograms for the resulting Rice factors were very similar and had means of 3.7 and $3.5 \mathrm{~dB}$ for 2 and $6 \mathrm{GHz}$, respectively. Mean values for the NLOS streets were approximately the same in the two bands. However, there was a noticeable difference on LOS street sections. On these streets, the mean was $8.6 \mathrm{~dB}$ at $2 \mathrm{GHz}$ and $4.4 \mathrm{~dB}$ at $6 \mathrm{GHz}$.

The distribution and cross correlation of envelope fading at Rake fingers, as well as Rake diversity gains that would be available to a spread spectrum receiver with maximum ratio combining (MRC), were also studied. Rake fingers were assumed to be synchronized to the delay of the strongest XCE peak and at two other delays, $300 \mathrm{~ns}$ on either side of it. ${ }^{2}$ Only three fingers were considered, as the relative power in XCEs was usually below $-20 \mathrm{~dB}$ beyond the $300-n s$ excess delay. It was found that Rayleigh and Rician fading models were only occasionally appropriate. Fade ranges between the tenth and ninetieth percentiles were therefore compared rather than Rice factors. Table I shows results for the paired data files. At the median, ${ }^{3}$ the increase in instantaneous received power averaged over $1 \mathrm{~s}$, or available MRC diversity gain, can be seen to be within $1 \mathrm{~dB}$ at 2 and $6 \mathrm{GHz}$. Fading ranges on the Rake fingers are also shown to be approximately equal. Envelope fading correlations among all fingers were low, regardless of frequency band. Finally, it can be seen in the table that the median powers at fingers 2 and 3 relative to that at finger 1 were also approximately equal in the two frequency bands.

The Rake finger data were applied in estimation of average probability of error for a spread spectrum binary phase-shift keying (BPSK) receiver with three Rake fingers and MRC. The assumption of a high spreading factor, i.e., 67 (which allows $>56.6 \mathrm{kbps}$ ), coupled with one that multipath delays occur at integer values of the spreading chip period, was used to permit modeling of self interference as being approximately Gaussian, with variance equal to the spreading factor [21]. This allows the variance of the self interference to be added to that of the noise so that the equation for BPSK probability of error on a nonfading channel can be averaged over the measured XCE time series. Results indicate that, at the median, to achieve a probability of error of $10^{-3}$, a bit energy to noise power spectral density $\left(E_{b} / N_{0}\right)$ ratio of $12 \mathrm{~dB}$ would be required at $2 \mathrm{GHz}$ in locations corresponding to the paired data files and that only $1 \mathrm{~dB}$ more would be needed at $6 \mathrm{GHz}$.

\section{CONCLUSION}

Results from the analysis of CW measurements reported herein lead to the conclusion that in downtown Ottawa, the difference between transmission loss at 2 and $6 \mathrm{GHz}$ can be modeled as having a lognormal distribution. Assuming similar feed system losses at the two frequencies, the mean of this model should be approximately equal to the difference in the effective apertures of receive antennas, and its standard deviation should be about $4 \mathrm{~dB}$. It is also concluded that the mean can vary by about $\pm 5 \mathrm{~dB}$ with respect to the ratio of effective apertures. These conclusions are largely in agreement with those reported on the basis of a similar study in a residential district of Tokyo, Japan [3].

KS tests on ECDFs reported in this paper indicate that there is no reason to reject a hypothesis that the underlying distributions of rms delay spreads at 2 and $6 \mathrm{GHz}$ are the same. Analysis results also show that variations of 2- and 6-GHz rms delay spreads as a function of location within the area where measurements were made are highly correlated.

\footnotetext{
${ }^{2}$ This spacing represents 1.5 sounder resolution intervals; fading at fingers with closer spacing would be too highly correlated for consideration in realistic diversity studies.

${ }^{3}$ This refers to the median of 31 results at each frequency for the paired files.
} 
TABLE I

RAKE FINGER AND MRC STATISTICS

\begin{tabular}{|c|c|c|c|c|c|c|c|c|c|c|c|}
\hline \multirow[t]{2}{*}{$\begin{array}{c}\text { Frequency } \\
\text { Band } \\
\text { (GHz) }\end{array}$} & \multirow[t]{2}{*}{$\begin{array}{l}\text { Median Diversity } \\
\text { Gain from MRC } \\
\text { (dB) }\end{array}$} & \multicolumn{4}{|c|}{$\begin{array}{c}\text { Median Envelope } \\
\text { Fade Range (dB)** }\end{array}$} & \multicolumn{3}{|c|}{$\begin{array}{c}\text { Median Envelope } \\
\text { Fading Correlation** }\end{array}$} & \multicolumn{3}{|c|}{$\begin{array}{c}\text { Median Relative } \\
\text { Average } \\
\text { Power }(\mathbf{d B})^{* *}\end{array}$} \\
\hline & & 1 & 2 & 3 & $\mathbf{S}^{*}$ & 1,2 & 1,3 & 2,3 & 1 & 2 & 3 \\
\hline 2 & 5.5 & 13 & 14 & 13 & 7.8 & .09 & .04 & .06 & 0 & -5 & -11 \\
\hline 6 & 4.9 & 13 & 13 & 13 & 8.5 & .0002 & .003 & .02 & 0 & -7 & -10 \\
\hline $\begin{array}{r}* \text { S is the } \\
\text { local }\end{array}$ & the sum $c$ & & 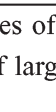 & & 1 & & & ue & & & \\
\hline
\end{tabular}

Frequency correlation characteristics, compared through the estimation of 3-D frequency correlation function volumes, are also concluded to be similar in the area where the measurements were made. KS tests showed that a hypothesis that the distributions of such volumes are the same cannot be rejected.

Statistics of narrowband envelope fading showed that globally, Rice factor distributions, and hence fade depths, are also approximately the same at 2 and $6 \mathrm{GHz}$ on NLOS streets. It was found, however, that there is a possibility of greater $\mathrm{CW}$ fade depths at $6 \mathrm{GHz}$ on LOS streets. The analysis of fading at equally spaced excess delays in XCEs showed that for spread spectrum systems with 5-MHz bandwidths, there would be very little difference in Rake finger envelope fading characteristics and available MRC diversity gain at 2 and $6 \mathrm{GHz}$.

The foregoing conclusions indicate that mobile link performance would be very similar at 2 and $6 \mathrm{GHz}$ in systems designed to result in equivalent received SNRs at both frequencies. This was verified by estimating the probability of error for mobile spread spectrum links operating with BPSK and a spreading factor of 67 based on time series analysis of the measured wideband data.

Greater Doppler spreads at $6 \mathrm{GHz}$, however, warrant careful consideration of whether or not the same frame lengths and channel estimation intervals can be used. Care must also be taken to ensure that symbol durations remain much shorter than coherence times at the higher frequencies in order to ensure no additional degradation as a result of time-selective fading.

\section{ACKNOWLEDGMENT}

The authors would like to thank Dr. G. Brussaard and Dr. M. Herben at Eindhoven University of Technology (TU/e) for helpful discussions, T. Smith and R. Berube at the Communications Research Centre (CRC) for technical support, L. Augustin and R. van Poppel, students at TU/e who worked at CRC during work terms contributing to their M.Sc. degrees, and J. Han, an M.Sc. student at Carleton University, for analyzing the Rake fading data.

\section{REFERENCES}

[1] V. Erceg, A. J. Rustako, and R. S. Roman, "Diffraction around corners and its effects on the microcell coverage area in urban and suburban environments at $900 \mathrm{MHz}, "$ IEEE Trans. Veh. Technol., vol. 43, no. 3, pp. 762-766, Aug. 1995.

[2] Y. Oda, R. Tsuchihashi, K. Tsunekawa, and M. Hata, "Measured path loss and multipath propagation characteristics in UHF and microwave frequency bands for urban mobile communications," in Proc. IEEE VTC-Spring Conf., May 2001, vol. 1, pp. 337-341.

[3] N. Kita, S. Uwano, A. Sato, and M. Umehira, "A path loss model in residential areas based on measurement studies using a 5.2-GHz/2.2-GHz dual band antenna," IEICE Trans. Commun., vol. E84-B, no. 3, pp. 368376, Mar. 2001.

[4] R. J. C. Bultitude and T. C. W. Schenk, "Microcellular mobile radio channel temporal dispersion and transmission loss characteristics at $1.9 \mathrm{GHz}$ and $5.8 \mathrm{GHz}$," in Proc. COST273, Towards Mobile Broadband Multimedia Netw., Barcelona, Spain, Jan. 2003, pp. 1-12. TD(03)015.

[5] T. C. W. Schenk, R. J. C. Bultitude, L. M. Augustin, R. H. van Poppel, and G. Brussaard, "Analysis of propagation loss in urban microcells at $1.9 \mathrm{GHz}$ and $5.8 \mathrm{GHz}$," in Proc. URSI Commission F Open Symp. Radiowave Propag. and Remote Sens., Feb. 2002, pp. 1-6.

[6] J. H. Whitteker, "Measurements of path loss at $910 \mathrm{MHz}$ for proposed microcell urban mobile system," IEEE Trans. Veh. Technol., vol. 37, no. 3, pp. 125-129, Aug. 1988.

[7] G. H. Bryant, R. J. C. Bultitude, and M. J. Neve, "A spatial field model for mobile radio," in Proc. 8th URSI Commission F Triennial Open Symp. Wave Propag. and Remote Sens., Sep. 1998, pp. 220-223.

[8] J. B. Andersen, "Statistical distributions in mobile communications using multiple scattering," in Proc. URSI XXVIIth Gen. Assem., Maastricht, The Netherlands, Aug. 2002, pp. 1-4.

[9] J. B. Andersen and I. Kovacs, "Power distributions revisited," in Proc. COST273, Towards Mobile Broadband Multimedia Netw., Guildford, U.K., Jan. 2002, pp. 1-13. TD(02)004.

[10] Y. Oda, K. Tsunekawa, and M. Hata, "Advanced LOS path-loss model in microcellular mobile communications," IEEE Trans. Veh. Technol., vol. 49, no. 6, pp. 2121-2125, Nov. 2000.

[11] H. M. El-Sallabi, "Fast path loss prediction by using virtual source technique for urban microcell," in Proc. IEEE VTC_Spring Conf., May 2001, vol. 3, pp. 2183-2187.

[12] W. Zhang and N. Moayeri, "Explicit expressions for the prediction of micro-cellular mobile radio propagation in urban street grid environments," in Proc. IEEE A\&P Soc. Int. Symp., 2000, pp. 1118-1121.

[13] E. S. Sousa, V. M. Jovanovic, and C. Daignault, "Delay spread measurements for the digital cellular channel in Toronto," IEEE Trans. Veh. Technol., vol. 33, no. 4, pp. 837-847, Nov. 1994.

[14] J. S. Bendat and A. G. Piersol, Measurement and Analysis of Random Data. New York: Wiley, 1966, pp. 219-223.

[15] W. J. Dixon and F. J. Massey, Introduction to Statistical Analysis, 3rd ed. New York: McGraw-Hill, 1969, pp. 345-347.

[16] R. von Mises, Mathematical Theory of Probability and Statistics. New York: Academic, 1964, pp. 490-493.

[17] R. J. C. Bultitude, "Estimating frequency correlation functions from propagation measurements on fading radio channels: A critical review," IEEE J. Sel. Areas Commun., vol. 20, no. 6, pp. 1133-1143, Aug. 2002.

[18] B. H. Fleury, "New bounds for the variation of mean-square-continuous wide-sense-stationary processes," IEEE Trans. Inf. Theory, vol. 41, no. 3 , pp. 849-852, May 1995.

[19] R. J. C. Bultitude and A. W. Leslie, "Propagation measurement based probability of error predictions for digital land mobile radio," IEEE Trans. Veh. Technol., vol. 46, no. 3, pp. 717-729, Aug. 1997.

[20] L. J. Greenstein, D. G. Michelson, and V. Erceg, "Moment method estimation of the ricean K-factor," IEEE Commun. Lett., vol. 3, no. 6, pp. 175176, Jun. 1999

[21] N. Adnani, "Rake receiver performance in direct sequence spread spectrum systems operating at high data rates," Ph.D. dissertation, Carleton Univ., Ottawa, ON, Canada, Apr. 2004. 


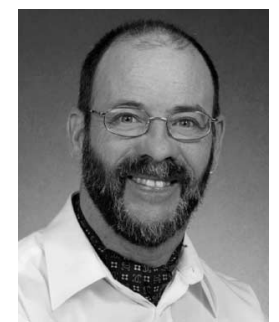

Robert J. C. Bultitude (S'74-M'78-SM'00) received the B.Sc.(Eng.) degree from the University of New Brunswick, Fredericton, NB, Canada, in 1975 and the M.Eng. and Ph.D. degrees from Carleton University, Ottawa, ON, Canada, in 1979 and 1987, respectively.

He was with Hoyles Niblock Associates, Consulting Telecommunications Engineers, Vancouver, BC, Canada, from 1975 to 1977 , as a Telecommunications Systems Engineer. In 1980, he was with Leigh Instruments, Ottawa, where he worked on radar head-end systems. Then, he joined the Communications Research Centre (CRC), Ottawa, in 1981. From 1981 to 1989, he was a Telecommunications Research Engineer working on radio propagation research for applications in mobile radio systems. From 1989 to 2000, he was the Manager of CRC's Land Mobile and Indoor Radio Propagation Research Group. During 1998-2000, he was with the Eindhoven University of Technology, Eindhoven, The Netherlands, as a Visiting Scientist, collaborating on mobile radio channel modeling. Since 2000, he has been with CRC as a Senior Research Scientist, working on mobile radio propagation measurements and channel modeling and actively participating in the European COST273 action concerned with mobile radio research. He is an Adjunct Professor with the Department of Systems and Computer Engineering, Carleton University.

Dr. Bultitude is a member of Sigma Xi. He received the Neal Shepherd Memorial Best Propagation Paper Award from the IEEE Vehicular Technology Society in 1997. He also received a Natural Sciences and Engineering Research Council Canada Discovery Grant, which is used to fund some of his graduate students.

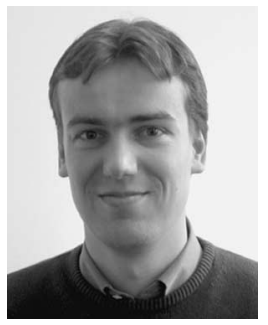

Tim C. W. Schenk (S'01-M'07) received the M.Sc. and Ph.D. degrees in electrical engineering from Eindhoven University of Technology (TU/e), Eindhoven, The Netherlands, in 2002 and 2006, respectively. The dissertation topic for his Ph.D. degree concerned the digital compensation of front-end impairments in multiple-antenna multicarrier systems.

As part of his master's program, in 2001, he spent four months with the Communications Research Centre, Ottawa, ON, Canada, as a Visiting Researcher. From 2002 to 2004, he was with the Wireless Systems Research group at Agere Systems, Nieuwegein, The Netherlands. From 2004 to 2006, he was a Research Assistant in the Radiocommunications group at TU/e. In October 2006, he joined the Connectivity Systems and Networks Department at Philips Research Laboratories, Eindhoven, The Netherlands, as a Research Scientist. His current interests include wireless communications, signal processing, and radio propagation modeling.

Dr. Schenk is a member of the Royal Institute of Engineers (KIvI) in The Netherlands and the Dutch Electronics and Radio Society (NERG).

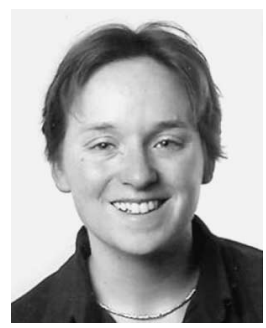

Nicole A. A. Op den Kamp received the M.Sc. degree in electrical engineering from the Eindhoven University of Technology, Eindhoven, The Netherlands, in 2003.

In 2001, she spent four months with the Communications Research Centre, Ottawa, ON, Canada, as a Visiting Researcher, carrying out research on radio wave propagation in microcells. She is currently with the RF Coil Electronics Group, Philips Medical Systems, Best, The Netherlands, working as a Hardware Developer of MR systems.

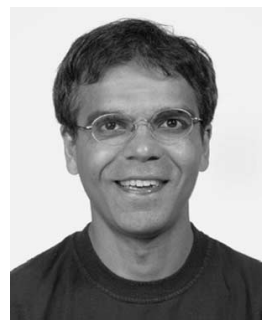

Nikhil Adnani received the B.Sc. and M.Sc. degrees in electrical engineering from the University of Manitoba, Winnipeg, MB, Canada, in 1994 and 1996, respectively. He received the Ph.D. degree in electrical engineering from Carleton University, Ottawa, ON, Canada, in 2004. His dissertation topic for his Ph.D. degree concerned the estimation of the performance of Rake receivers in DSSS systems operating at high data rates.

From 1996 to 1998, he was with Nortel Networks, Ottawa, as a member of Scientific Staff, working on the design of frequency synthesizers for CDMA base stations. He is currently with the Communications Research Centre, Ottawa, as a Research Engineer. His research interests are in the areas of signal processing and receiver design for wireless communication systems. 